Original Article (short paper)

\title{
Estimated intensity and acute cardiovascular response to a single exercise session guided by the fitness app Sworkit ${ }^{\circledR}$ Personal Trainer
}

\author{
Adeilson Serra Mendes Vieira ${ }^{1,2}\left(\mathbb{D}\right.$, Antonio Carlos Silva-Filho ${ }^{1,3}$, Sara Raquel Dutra-Macêdo ${ }^{1,2}$, \\ Carlos José Dias ${ }^{1,3}\left(\mathbb{D}\right.$, Bruno Rodrigues ${ }^{4}$, Cristiano Teixeira Mostarda ${ }^{1,2,3,5}$ (1)

\begin{abstract}
${ }^{1}$ Universidade Federal do Maranhão, UFMA, Laboratory of Cardiovascular Adaptations to Exercise, LACORE, São Luís, MA, Brazil; ${ }^{2}$ Universidade Federal do Maranhão, UFMA, Programa de Pós-Graduação em Saúde do Adulto, São Luís, MA, Brazil; ${ }^{3}$ Universidade Federal do Maranhão, UFMA, Programa de Doutorado em Biotecnologia - Rede Nordeste de Biotecnologia, São Luis, MA, Brazil; ${ }^{4}$ Universidade Estadual de Campinas, UNICAMP, Faculty of Phisical Education, Campinas, SP, Brazil;

${ }^{5}$ Universidade Federal do Maranhão, UFMA, Programa de Pós-Graduação em Educação Física, São Luís, MA, Brazil
\end{abstract}

\begin{abstract}
Aim: The aim of the present study was to evaluate the effect of an exercise session prescribed by the Sworkit ${ }^{\mathbb{B}}$ Personal Trainer application on hemodynamic and autonomic responses. Methods: The sample consisted of 11 men classified as sedentary according to IPAQ. The exercises were randomly selected by the app Sworkit ${ }^{\circledR}$ Personal Trainer, using the pre-built program "Light Warm-Up Cardio" (see supplementary material). Heart rate and perceived exertion data were collected every minute during an exercise session. Blood pressure and heart rate variability were measured Pre, Post, $30 \mathrm{~min}, 12 \mathrm{~h}, 24 \mathrm{~h}$, and $48 \mathrm{~h}$ after exercise. Heart rate and rate of perceived exertion were collected during the 30 minutes exercise. Results: Hemodynamic responses showed differences in heart rate and systolic blood pressure: Post, $12 \mathrm{~h}$ and $24 \mathrm{~h}$ compared to Pre. We also found significant statistical differences in the heart rate variability indexes when comparing Post, $30 \mathrm{~min}$ to $48 \mathrm{~h}$ versus Pre, indicating modifications in the autonomic modulation post-exercise. The perceived exertions scale remained between 13-14 during the exercise. Heart rate was $149 \pm 5.26(80 \pm 5 \%$ of HRmax) during the $30 \mathrm{~min}$ exercise, indicating a moderate to vigorous intensity. Conclusion: We concluded that a single exercise session guided by the Sworkit ${ }^{\circledR}$ Personal Trainer application could generate autonomic changes in up to 12 hours, presenting a moderate to vigorous intensity in 30 minutes of exercise for sedentary men.
\end{abstract}

Keywords: heart rate variability, fitness app, exercise, blood pressure.

\section{Introduction}

A sedentary lifestyle is recognized as one of the significant causes of mortality and onset of chronic non-communicable diseases around the world ${ }^{1}$. Given this, several initiatives have been developed aiming stimulus for the practice of physical activity. Among them, the "apps", i.e., mobile applications that stimulate physical 8activity engagement, are one of the most recent ${ }^{2,3}$.

In today's world, smartphones are more present than computers, with more than 4.77 billion devices in $2017^{4}$, demonstrating that fitness apps are an excellent gateway for stimulating the practice of physical activity. Among all these applications, the app called Sworkit ${ }^{\circledR}$ Personal Trainer, with more than five million downloads, has an organized training program, using only body weight and some small exercise equipment like dumbbells and mats to stimulate the practice of physical activity within a small space, like that of an ordinary apartment. The Sworkit ${ }^{\circledR}$ Personal Trainer app has been one of the most acclaimed apps in use, with a recent review pointing out that the Sworkit ${ }^{\circledR}$ Personal Trainer app exercise program accomplishes some of the American College of Sports Medicine (ACSM) recommendations ${ }^{2}$. However, the fitness apps nor display the intensity of the proposed exercises, neither how the subject can control it, turning the exercise too vigorous or too light for the proposed objective.

Also, with the advancement of technology, it becomes important to evaluate the applicability of apps that prescribe exercises without professional supervision. In addition, the app does not make clear to users the limitations of the app and also does not consider the specific characteristics of each individual, such as age, sex, risk factors, and previous exercise experience.

We hypothesize that an exercise guided by the fitness app is of high intensity, leading to increased sympathetic modulation and low overall variability right after the exercise session. Therefore, we aimed to evaluate the intensity of an exercise session guided by the Sworkit ${ }^{\circledR}$ Personal Trainer application and its effects on cardiovascular autonomic modulation.

\section{Methods}

The present study was carried out in accordance with resolution 466/12 of the Conselho Nacional de Saúde (CNS) and was approved by the local ethics committee under the number: 1.378.131. 


\section{Sample}

The sample was composed of 11 young male recruited from the local community after a public call. Subjects with muscular or joint diseases, cardiovascular and/or metabolic diseases that prevented them from performing the exercise session were not included in the study. Individuals who did not complete all stages of the collection protocol were excluded from the study. Participants were classified according to their weekly physical activity levels based on the International Physical Activity Questionnaire (IPAQ), which classifies as sedentary individuals who did not perform any physical activity for at least ten continuous minutes in the last seven days. The Physical Activity Readiness Questionnaire (PAR-Q) was applied prior to the exercise protocol, to screen for any unknown cardiovascular risk factors. All participants were informed of the procedures involved in the study and signed an Informed Consent form. Also, the procedures in the study were carried out according to the National Health Council and the Helsinki Guidelines.

\section{Body composition}

Body mass measurements were determined with a digital scale (Beurer GmbH, Soflinnger Strabe 218, Uml, Germany), graduated from 0 to $180 \mathrm{~kg}$, with an accuracy of $0.1 \mathrm{~kg}$; and height with the use of a wooden stadiometer (WCS, Econômico Wood, Curitiba-PR), with a precision scale of $0.1 \mathrm{~cm}$, graduated from 20 to $220 \mathrm{~cm}$; an anthropometric tape (Starret, SN-4010, Sanny, Brasil), made in steel material, graduated in millimeters $(\mathrm{mm})$ (6). The body mass index (BMI) of the sample was calculated by the body mass/stature ${ }^{2}$ ratio, with the body mass expressed in $(\mathrm{kg})$ and the height in $(\mathrm{m})$. The waist-to-hip ratio of the sample was calculated by dividing the waist by the hip circumferences expressed in (cm).

\section{Blood Pressure}

Systolic blood pressure (SBP) and diastolic (DBP) was verified using an automated blood pressure monitor (OMRON, HEM-7200, São Paulo, Brazil), according to the national guidelines described elsewhere 5 .

\section{Heart Rate Variability (HRV)}

An electrocardiogram device (Micromed Wincardio 600hz, Brasília, DF, Brazil) was used for the analysis of HRV. The spectrum resulting from the Fast Fourier Transforms modelling is derived from all the data present in a minimum five-minute window from the recorded signal; it includes the entire signal variance, regardless of whether its frequency components appear as specific spectral peaks or as nonpeak broadband powers. We used the following HRV indexes: Total variance $\left(\mathrm{ms}^{2}\right)$, mean of all RR intervals (ms), SDNN (ms, standard deviation of all normal to normal intervals), RMSSD (ms, root mean square of the successive differences of the normal to normal intervals), LF (0.04-0.15 Hz; $\mathrm{ms}^{2}$ and, normalized units, low-frequency spectral density), HF (0.15-0.4 Hz; $\mathrm{ms}^{2}$, and normalized units, high-frequency spectral density), LF/HF (ratio of low and high frequency domains).

The symbolic analysis, i.e., the distribution of the patterns was calculated to provide a quantification of the complexity of the pattern distribution. All possible patterns (i.e., 216) were grouped without any loss into three families referred to as (1) patterns with no variation. The sequences are spread on six levels, and all possible patterns are divided into four groups as described by Guzzetti et al. ${ }^{6}$. The analysis consists of patterns with 1$)$ no variations $(0 \mathrm{~V}$, three symbols equal, associated with sympathetic modulation); 2 ) one variation ( $1 \mathrm{~V}$, two symbols equal and one different associated with sympathetic and parasympathetic modulation); 3 ) two like variations (2LV and associated with parasympathetic modulation); and 4) two unlike variations (2UV and associated with parasympathetic modulation). Additionally, the nonlinear analysis of HRV was evaluated by the entropy indexes.

\section{Maximal Heart Rate Test (HRmax)}

Participants underwent a maximal stress test one week before the training session to obtain the HRmax and perceived exertion (PE) of the individuals. For this, the Bruce protocol was used for the maximal test, while the Heart Rate (HR) (Polar FT1) and PE were checked every minute during the test. After the test, the $\mathrm{VO}_{2}^{\max }$ was estimated indirectly by the following equation for $\mathrm{men}^{7}$ :

$V O_{2}^{\max }=14.8-(1.379 \times$ Time $)+(0.451 \times$ Time 2$)-\left(0.012 \times\right.$ Time $\left.^{3}\right)$

\section{Exercise session}

One day before the training session, the participants went through familiarization of the exercises, as well as the functioning of the application. The training session was conducted by the app Sworkit ${ }^{\circledR}$ Personal Trainer - version 7.3.7, in Brazilian Portuguese which contains training programs for various purposes.

The training session consisted of series of exercises with 30 seconds of duration, pauses of 5 seconds and intervals of 30 seconds every 2 minutes of exercise, to a total of 30 minutes, the minimal amount of exercise recommended by the ACSM's guidelines $^{8}$. The application does not take into account the breaks and intervals, counting only 30 minutes of actual exercise. Subjects were guided only by the app instructions and no external stimuli or exercise execution instructions were given during the exercise session. The "Light Warm-Up Cardio" exercise program was used in this study and was chosen mainly because its proposed for beginners, seen that the subjects of the study were sedentary. The exercise order was randomly selected by the app among 14 exercises composing the exercise program (see supplementary Table and Figure). 


\section{Exercise HR monitoring and energy expenditure estimation}

HR was monitored during exercise. We calculated the percentage of the maximal HR achieved during the exercise (\%HRmax) for intensity determination. We also used the 6-20 Borg's Perceived Exertion scale 9 , to identify the rate of PE, collected from each during the exercise session at every minute. The energy expenditure was estimated based on the formula created by Keytel and colleagues ${ }^{10}$. Briefly, the formula takes into account the HR, the duration of exercise, the age and body weight of the subjects to estimate the energy expenditure from the HR.

\section{Statistical analysis}

To compare all responses between moments, we used the One-Way ANOVA for repeated measures with Tukey's posthoc, assuming a 95\% confidence interval, with $\mathrm{p}<0.05$. All results are expressed in mean and standard deviations. The GraphPad Prism 5 software was used for the statistical analysis and graph drawing.

\section{Results}

The overall characteristics of the sample are described in table 1 . When comparing the measurements of SBP, a

RR
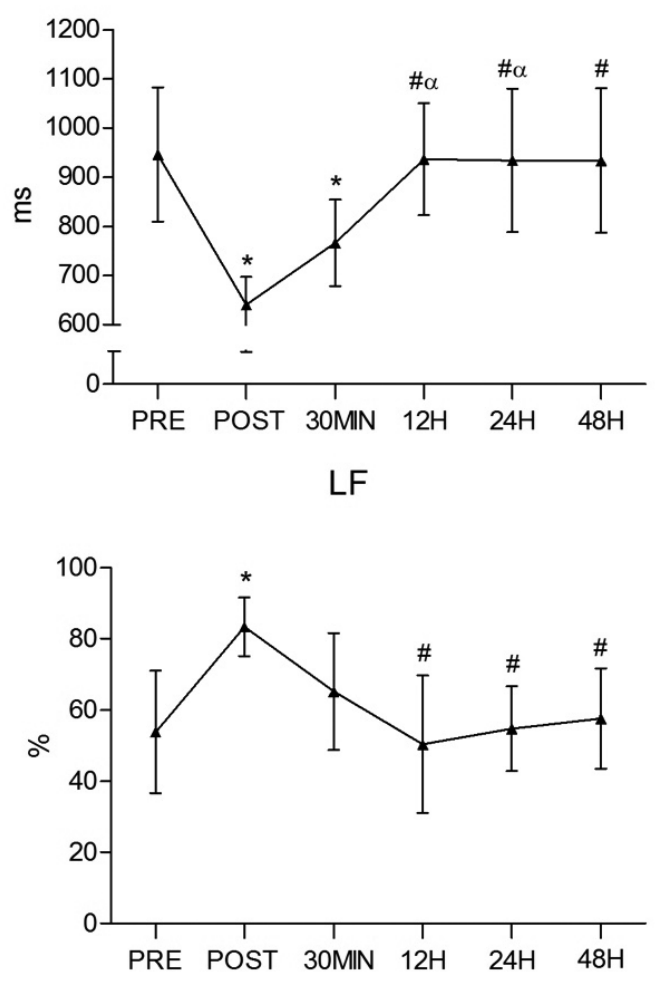

significant difference was found only in the analysis of $30 \mathrm{~min}$ after exercise versus Post, whereas the measures of DBP showed no differences. In HR we also found significant differences in $12 \mathrm{~h}$ and $48 \mathrm{~h}$ measurements compared to 30 $\min (\mathrm{p}<0.05$; Table 2$)$.

Table 1. Overall sample characterization

\begin{tabular}{lc}
\hline & $\mathbf{N}=\mathbf{1 1}$ \\
\hline Weight $(\mathrm{kg})$ & $74.05 \pm 9.17$ \\
Height $(\mathrm{m})$ & $1.71 \pm 0.07$ \\
Age $($ years $)$ & $24.64 \pm 3.98$ \\
Body mass index $\left(\mathrm{kg} / \mathrm{m}^{2}\right)$ & $24.99 \pm 1.97$ \\
Waist ratio hip ratio $(\mathrm{cm})$ & $0.84 \pm 0.03$ \\
Estimated $\mathrm{VO}_{2}^{\max }(\mathrm{mL} / \mathrm{kg} * \min )$ & $39.31 \pm 4.34$ \\
IPAQ minutes/week & $17.6 \pm 25.4$ \\
Energy expenditure $(\mathrm{kcal})$ & $420 \pm 32.7$ \\
HRmax $(\mathrm{bpm})$ & $186.8 \pm 4.7$ \\
\hline
\end{tabular}

In the time domain indexes, total variance, RR, SDNN, and RMSSD showed significant differences in the Post and 30 min versus Pre-measurements. In addition to differences in measures $12-48 \mathrm{~h}$ versus Post and differences in the measure of $12 \mathrm{~h}$ versus $30 \mathrm{~min}$. In the frequency domain, they showed significant differences in the Post versus Pre-measure and in the 12-48 hour measures versus Post $(\mathrm{p}<0.05$; Table 2).

RMSSD
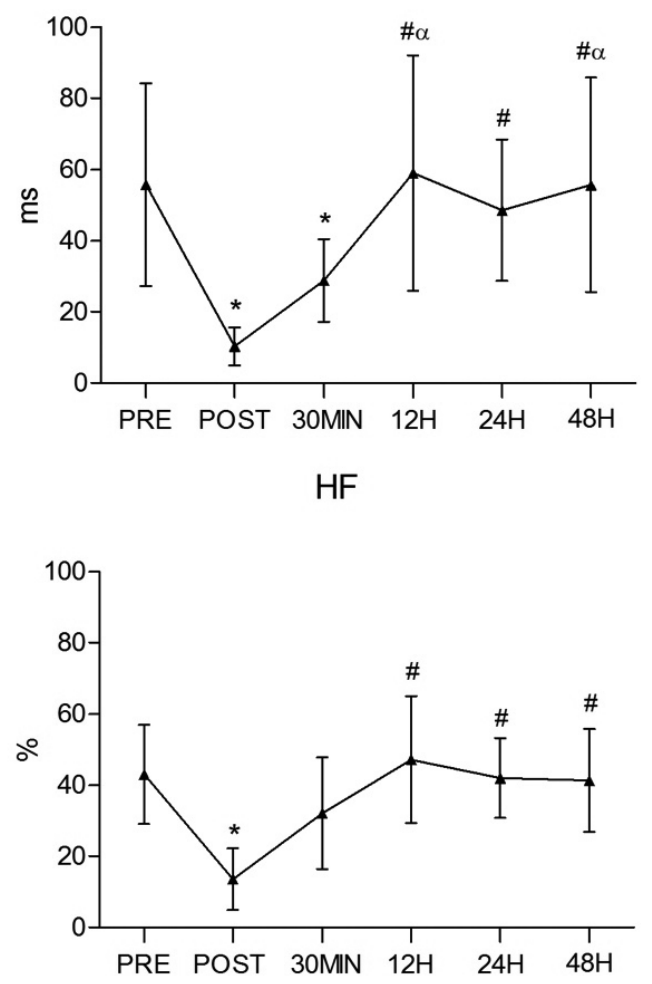

Figure 1. Time and frequency domain.

$* \mathrm{p}<0.05$ versus pre; $\# \mathrm{p}<0.05$ versus post. 
In the nonlinear domain, they presented significant differences in the SD1, SD2, SD1 / SD2, SampEn and $\mathrm{CE}$ indices in the Post versus Pre measurement and in the 12-48h measures versus Post ( $<<0.05$; Table 2).

The symbolic analysis showed significant differences in the $0 \mathrm{~V}, 2 \mathrm{LV}$, and $2 \mathrm{UV}$ when comparing Post versus Pre, and, $12-48 \mathrm{~h}$ versus Post $(\mathrm{p}<0.05$; Table 2$)$. However, the $1 \mathrm{~V}$ did not show any difference between any moment.

The HR and RPE were monitored during exercise to understand its intensity. The increasing trend is

\section{HEART RATE}

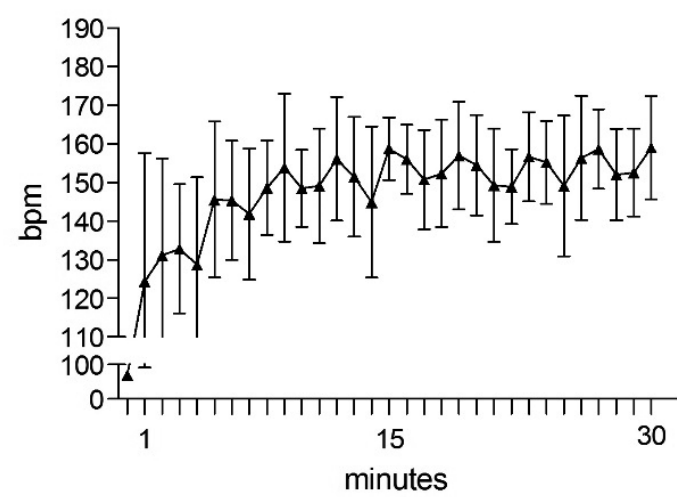

Figure 2. Comparison between HR and PE at each minute of exercise.

\section{Discussion}

This study aimed to evaluate the effect of an exercise session guided by the Sworkit ${ }^{\mathbb{R}}$ Personal Trainer app on hemodynamic and autonomic responses in healthy sedentary subjects. The major findings of this study suggest that a single exercise session prescribed by the fitness app was able to promote autonomic changes up to 12 hours, normalizing entirely or even overcompensating in some verified indexes between 24 and 48 hours post-exercise.

The intensity was classified as moderate to vigorous, according to the HR, \% HRmax, and RPE, as stated by the ACSM's guidelines $^{8}$, differing from the app proposal, which ranks the "Light Warm-Up Cardio" program for beginners and being of low intensity.

The Sworkit ${ }^{\circledR}$ Personal Trainer app proposes training programs for aerobic, strength and flexibility exercises. The app presents training for both beginners and experienced trainers, seeking to reach a broader audience independent of gender and age. To the best of our knowledge, our study was the first to evaluate the intensity, hemodynamic and autonomic responses in healthy sedentary men using a fitness app. In this context, the heart rate variability has been used as an evaluation tool for exercise prescription ${ }^{11-13}$.

A significant increase of HR during exercise, with some subjects peaking $90 \%$ of the HRmax, shows that the program proposed by the app is moderate to vigorous (Figure 2 and 3). These increases in HR during exercise are mainly driven by the cardiac vagal withdrawal ${ }^{14}$. There is also an increase in the depicted in Figure 2. The mean HR during the $30 \mathrm{~min}$ of the exercise was $149 \pm 5.26 \mathrm{bpm}$, and the mean $\mathrm{PE}$ was $13 \pm 0.55$. Also, the HR achieved during exercise was compared to the HRmax achieved during a maximal HR test (\%HRmax), with a mean of $80 \pm 5$ percent during the $30 \mathrm{~min}$ of exercise (Figure 3).

The predicted exercise energy expenditure had a mean of $420 \pm 33 \mathrm{kcal}$, which corresponds to $5.73 \pm 0.67$ metabolic equivalents (MET).

\section{PERC EXERT}

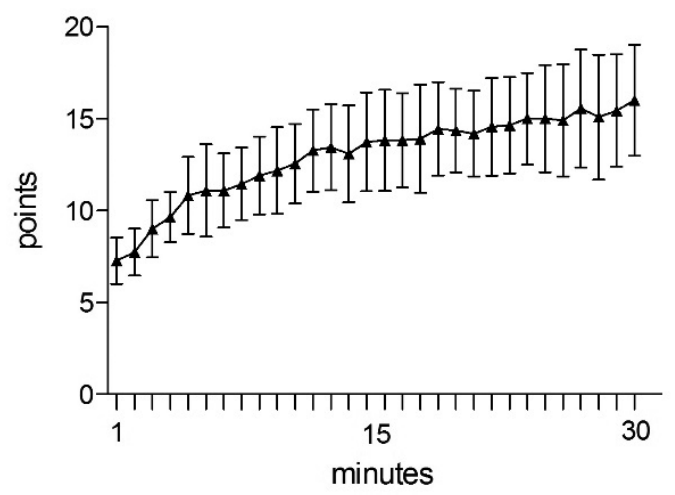

sympathetic nerve activity stimulated by the mechanoreceptors and metaboreceptors in the muscles during exercise, increasing the HR, and blood pressure ${ }^{15}$. The ACSM states that an exercise between $77-95 \%$ of the HRmax is considered vigorous ${ }^{8}$. In this study, subjects remained at $\sim 80 \%$ of the HRmax, indicating a vigorous intensity.

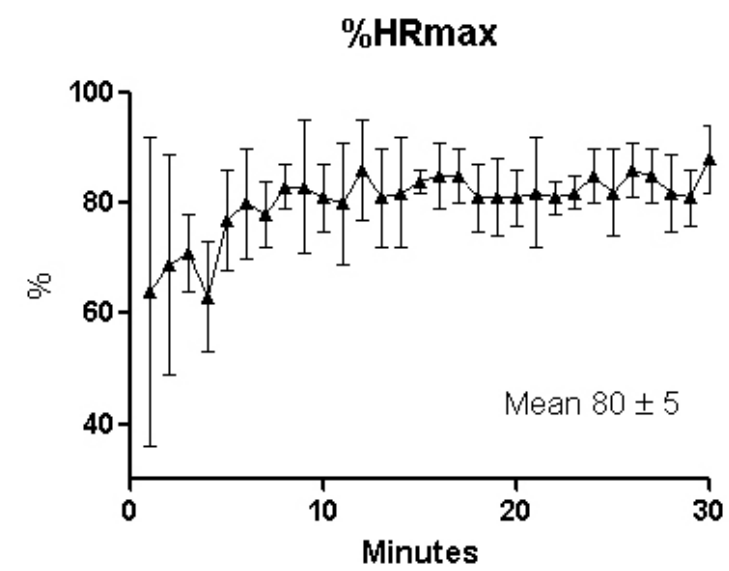

Figure 3. Percentage of HRmax reached every minute of exercise.

Dynamic exercises promote an increase in SBP and maintenance or reduction of DBP during exercise ${ }^{16}$, as found in the present study (Table 2). No significant increase in SBP immediately post-exercise was found but significant hypotension is described after 30 minutes of the exercise session (Table 2), which is in agreement with the literature for healthy young 
individuals ${ }^{17-20}$. Some studies have shown that after aerobic exercise, marked hypotension is found, which can be caused by either the reduction of peripheral vascular resistance or reduction of cardiac output ${ }^{21-23}$. Also, to corroborate the intensity of the exercised proposed by the app, we calculated the energy expenditure based on the HR, and remained in a mean of 5.7 MET's, indicated as moderate according to the ACSM's guidelines $^{8}$.

Table 2. Hemodynamic and autonomic indexes before and after exercise guided by the fitness app

\begin{tabular}{|c|c|c|c|c|c|c|}
\hline \multicolumn{7}{|c|}{$N=11$} \\
\hline & Pre & Post & $30 \mathrm{~min}$ & $12 \mathrm{~h}$ & $24 \mathrm{~h}$ & $48 \mathrm{~h}$ \\
\hline \multicolumn{7}{|c|}{ BLOOD PRESSURE } \\
\hline $\mathrm{SBP}(\mathrm{mmHg})$ & $123.73 \pm 11.73$ & $131.27 \pm 12.33$ & $119.00 \pm 12.85^{\#}$ & $122.55 \pm 10.50$ & $122.18 \pm 15.15$ & $124.18 \pm 13.44$ \\
\hline $\mathrm{DBP}(\mathrm{mmHg})$ & $72.27 \pm 11.82$ & $73.00 \pm 8.56$ & $71.36 \pm 8.58$ & $71.27 \pm 7.23$ & $68.73 \pm 7.04$ & $70.27 \pm 7.85$ \\
\hline \multicolumn{7}{|c|}{ TIME DOMAIN } \\
\hline Heart Rate (bpm) & $64.75 \pm 10.35$ & $94.38 \pm 8.6^{*}$ & $79.24 \pm 9.35^{* \#}$ & $64.92 \pm 7.9^{\# \alpha}$ & $65.62 \pm 9.95^{\# \alpha}$ & $65.53 \pm 8.98^{\# \alpha}$ \\
\hline Total var. $\left(\mathrm{ms}^{2}\right)$ & $4363 \pm 3393$ & $573 \pm 271^{*}$ & $1594 \pm 819^{*}$ & $5322 \pm 4984^{\# \alpha}$ & $4281 \pm 2412^{\#}$ & $4378 \pm 3020^{\#}$ \\
\hline $\mathrm{RR}(\mathrm{ms})$ & $946.37 \pm 136.51$ & $640.41 \pm 56.85^{*}$ & $766.64 \pm 88.17^{*}$ & $936.69 \pm 113.31^{\# \alpha}$ & $934.10 \pm 145.32^{\# \alpha}$ & $933.76 \pm 146.80^{\#}$ \\
\hline SDNN (ms) & $61.33 \pm 28.99$ & $23.46 \pm 6.23 *$ & $37.62 \pm 9.70 *$ & $66.95 \pm 30.42^{\# \alpha}$ & $57.33 \pm 16.66^{\#}$ & $61.69 \pm 21.00^{\#}$ \\
\hline RMSSD (ms) & $55.80 \pm 28.53$ & $10.38 \pm 5.36^{*}$ & $28.87 \pm 11.67 *$ & $59.08 \pm 33.10^{\# \alpha}$ & $48.62 \pm 19.87^{\#}$ & $55.71 \pm 30.19^{\# a}$ \\
\hline \multicolumn{7}{|c|}{$\begin{array}{l}\text { FREQUENCY DOMAIN } \\
\end{array}$} \\
\hline $\mathrm{LF}\left(\mathrm{ms}^{2}\right)$ & $1195 \pm 1035$ & $245.22 \pm 202.89 *$ & $591 \pm 486$ & $1458 \pm 1746^{\#}$ & $1415 \pm 1602^{\#}$ & $1283 \pm 870^{\#}$ \\
\hline $\mathrm{HF}\left(\mathrm{ms}^{2}\right)$ & $917.45 \pm 562.63$ & $44.51 \pm 53.00^{*}$ & $234.40 \pm 186.96^{*}$ & $1157 \pm 1053^{\# \alpha}$ & $855.69 \pm 602.70^{\#}$ & $1882 \pm 1386^{\# \alpha}$ \\
\hline LF (nu) & $53.89 \pm 17.16$ & $83.41 \pm 8.29^{*}$ & $65.21 \pm 16.39$ & $50.41 \pm 19.29^{\#}$ & $54.78 \pm 11.90^{\#}$ & $57.62 \pm 14.12^{\#}$ \\
\hline HF (nu) & $43.04 \pm 13.95$ & $13.60 \pm 8.63^{*}$ & $32.12 \pm 15.70$ & $47.20 \pm 17.82^{\#}$ & $42.08 \pm 11.25^{\#}$ & $41.36 \pm 14.48^{\#}$ \\
\hline $\mathrm{LF} / \mathrm{HF}$ & $1.55 \pm 1.03$ & $9.60 \pm 6.66^{*}$ & $2.86 \pm 2.41$ & $1.44 \pm 1.15^{\#}$ & $1.50 \pm 0.87^{\#}$ & $1.75 \pm 1.11$ \\
\hline \multicolumn{7}{|c|}{ NONLINEAR DOMAIN } \\
\hline SD1 (ms) & $43.75 \pm 17.19$ & $7.61 \pm 3.88^{*}$ & $20.36 \pm 7.98^{*}$ & $42.42 \pm 22.65^{\#}$ & $37.30 \pm 14.41^{\#}$ & $44.40 \pm 23.13^{\# \alpha}$ \\
\hline $\mathrm{SD} 2(\mathrm{~ms})$ & $74.34 \pm 30.08$ & $31.96 \pm 7.91^{*}$ & $49.24 \pm 13.65$ & $78.45 \pm 37.05^{\# \alpha}$ & $79.64 \pm 21.93^{\#}$ & $75.30 \pm 22.21^{\#}$ \\
\hline $\mathrm{SD} 1 / \mathrm{SD} 2$ & $0.61 \pm 0.20$ & $0.22 \pm 0.07 *$ & $0.41 \pm 0.11$ & $0.55 \pm 0.17^{\#}$ & $0.47 \pm 0.11$ & $0.56 \pm 0.17^{\#}$ \\
\hline Sample Entropy & $1.57 \pm 0.32$ & $1.00 \pm 0.20^{*}$ & $1.34 \pm 0.22$ & $1.56 \pm 0.30^{\#}$ & $1.48 \pm 0.20^{\#}$ & $1.63 \pm 0.41^{\#}$ \\
\hline Current Entropy & $1.07 \pm 0.08$ & $0.74 \pm 0.10^{*}$ & $0.92 \pm 0.15$ & $1.07 \pm 0.12^{\#}$ & $1.01 \pm 0.08^{\#}$ & $1.07 \pm 0.12^{\#}$ \\
\hline \multicolumn{7}{|c|}{ SIMBOLIC ANALYSIS } \\
\hline OV (nu) & $13.96 \pm 6.68$ & $46.90 \pm 11.04^{*}$ & $31.06 \pm 15.25^{*}$ & $16.44 \pm 11.24^{\#}$ & $19.96 \pm 9.15^{\#}$ & $17.07 \pm 11.46^{\#}$ \\
\hline 1V (nu) & $45.12 \pm 6.57$ & $42.92 \pm 6.49$ & $44.29 \pm 5.34$ & $43.91 \pm 5.87$ & $48.45 \pm 3.29$ & $44.36 \pm 7.15$ \\
\hline $2 \mathrm{LV}(\mathrm{nu})$ & $12.55 \pm 4.33$ & $4.23 \pm 3.47 *$ & $8.70 \pm 6.52$ & $14.05 \pm 5.80^{\#}$ & $11.92 \pm 4.33$ & $12.97 \pm 4.90^{\#}$ \\
\hline 2UV (nu) & $28.37 \pm 10.48$ & $5.94 \pm 3.87 *$ & $15.95 \pm 7.41$ & $25.60 \pm 11.71^{\#}$ & $19.67 \pm 8.35$ & $25.47 \pm 10.12^{\#}$ \\
\hline
\end{tabular}

${ }^{*} \mathrm{p}<0.05$ versus pre; ${ }^{*} \mathrm{p}<0.05$ versus post; ${ }^{\alpha} \mathrm{p}<0.05$ versus $30 \mathrm{~min}$.

In the HRV analysis, all indexes with statistical significance show the same trend, as can be seen in Table 2 and Figure 1. The trend consists of increases in the sympathetic and decreases in vagal modulation right after exercise and up to $30 \mathrm{~min}$ after exercise, with recovery from $12-48 \mathrm{~h}$ after exercise, when the HRV returns to its baseline levels. The time domain shows reduced values for Mean RR, SDNN, RMSSD and Total variability up to $30 \mathrm{~min}$ after exercise, and recovers from 12-48h $(\mathrm{p}<0.05)$. The frequency domain; however, shows increased LF and decreased HF values after exercise, but recovers from $12-48 \mathrm{~h}(\mathrm{p}<0.05)$. The nonlinear methods and the symbolic analysis also follow the same trend, indicating higher sympathetic modulation up to $30 \mathrm{~min}$ after exercise, with the recovery from 12-48h (Table 2).

This pattern has been shown in several studies regarding acute exercise and HRV, as is an indicator of the exercise intensity ${ }^{11,14,24,25}$. Also, the HRV has been used as a tool for exercise prescription and training periodization ${ }^{12,13}$. Vigorous exercise workloads are followed by decreases in overall variability and increases in sympathetic modulation up to $24-48 \mathrm{~h}$, and moderate to intense workloads are known to recover from 12-24h after exercise, a pattern observed in our study, corroborating the exercise intensity from moderate to vigorous ${ }^{12,13,15}$.

During exercise, HR and RPE were monitored to understand the intensity of the exercise. The HR at the beginning of exercise remained around $110-140 \mathrm{bpm}$ in the initial $10 \mathrm{~min}$ and rose to approx. $170-180 \mathrm{bpm}$ at the end of the exercise session, but, as can be seen in figure 2, during the exercise session, the HR varies, indicating variability in the intensity. This variability is mainly due to the random nature of exercises prescribed by the app, which does not follow and logical organization (See supplementary material).

However, the RPE remained increasing, indicating that the summation of efforts during the $30 \mathrm{~min}$ of exercise caused the perceived intensity to rise (Figure 2). In the other hand, subjects submitted to the exercise session guided by the app are considered sedentary or inactive, according to the IPAQ questionnaire, which can lead to non-accurate perceived exertion, seen by the average RPE around 13-14, but the HR was around 180, indicating that subjects are not familiarized with exercising ${ }^{26}$. 
In conclusion, all these variables together set a position that the exercise guided by the app Sworkit ${ }^{\circledR}$ Personal Trainer has a moderate to vigorous intensity, differing from what is proposed by the program, which indicates that's it has a light intensity. The program has to be used with caution and, preferably, accompanied by an exercise professional, to avoid unnecessary risks. Also, other apps must be designed following the ACSM recommendations for quantity and quality of exercise, aiming to obtain safe and better results.

\section{References}

1. Schmidt MI, Duncan BB, E Silva GA, Menezes AM, Monteiro CA, Barreto SM, et al. Chronic non-communicable diseases in Brazil: Burden and current challenges. Lancet 2011; 377: 1949-1961.

2. Modave F, Bian J, Leavitt T, Bromwell J, Harris C, Vincent H. Low Quality of Free Coaching Apps With Respect to the American College of Sports Medicine Guidelines: A Review of Current Mobile Apps. JMIR mHealth uHealth 2015; 3: e77.

3. Higgins JP. Smartphone Applications for Patients' Health and Fitness. Am J Med 2015; 129: 11-19.

4. Poushter J. Smartphone ownership and internet usage continues to climb in emerging economies. Pew Res Cent; 22.

5. Malachias MVB, Souza W, Plavnik FL, Rodrigues CIS, Brandão AA, Neves MFT, et al. 7aDiretriz brasileira de hipertensão arterial. Arq Bras Cardiol 2016; 107: 1-103.

6. Guzzetti S, Borroni E, Garbelli PE, Ceriani E, Della Bella P, Montano N, et al. Symbolic dynamics of heart rate variability: A probe to investigate cardiac autonomic modulation. Circulation 2005; 112: 465-470.

7. Meneghelo RS, Araújo CGS, Stein R, Mastrocolla LE; Albuquerque PF; Serra SM, et al. III Diretrizes da Sociedade Brasileira de Cardiologia sobre teste ergométrico. Arq Bras Cardiol 2010; 95: 1-26.

8. Garber CE, Blissmer B, Deschenes MR, Franklin BA, Lamonte MJ, Lee IM, et al. American College of Sports Medicine position stand. Quantity and quality of exercise for developing and maintaining cardiorespiratory, musculoskeletal, and neuromotor fitness in apparently healthy adults: guidance for prescribing exercise. Med Sci Sports Exerc 2011; 43: 1334-1359.

9. Borg G. Borg's perceived exertion and pain scales. Hum Kinet 1998; 104.

10. Keytel LR, Goedecke JH, Noakes TD, Hiiloskorpi H, Laukkanen $\mathrm{R}$, van der Merwe L, et al. Prediction of energy expenditure from heart rate monitoring during submaximal exercise. J Sports Sci 2005; 23: 289-297.

11. Tulppo MP, Makikallio TH, Takala TE, Seppänen T, Huikuri $\mathrm{HV}$, et al. Quantitative beat-to-beat analysis of heart rate dynamics during exercise. Am J Physiol Circ Physiol 1996; 271: H244--H252.

12. Kiviniemi AM, Hautala AJ, Kinnunen H, Nissilä J, Virtanen P, Karjalainen J, et al. Daily exercise prescription on the basis of HR variability among men and women. Med Sci Sports Exerc 2010; 42: 1355-1363.
13. Kiviniemi AM, Hautala AJ, Kinnunen H, Tulppo MP. Endurance training guided individually by daily heart rate variability measurements. Eur J Appl Physiol 2007; 101: 743-751.

14. Yamamoto Y, Hughson RL, Peterson JC. Autonomic control of heart rate during exercise studied by heart rate variability spectral analysis. J Appl Physiol 1991; 71: 1136-1142.

15. Abad CCC, Silva RS da, Mostarda C, Silva ICM, Irigoyen MC. Efeito do exercício aeróbico e resistido no controle autonômico e nas variáveis hemodinâmicas de jovens saudáveis. Rev bras Educ Fis Esporte 2010; 24: 535-44.

16. Brum PC, Forjaz C, Tinucci T, Negrao CE. Adaptações agudas e crônicas do exercício físico no sistema cardiovascular. Rev Paul Educ Física 2004; 18: 21-31.

17. Angadi SIS, Hammar DHMB, Aesser GLAG. Postexercise hypotension after continuous, aerobic interval, and sprint interval exercise. J Strength Cond Res 2015; 29: 2888-2893.

18. Casonatto J, Domingues V, Christofaro DGD. Impacto do exercício contínuo e intervalado na resposta autonômica e pressórica em 24 horas. Rev Bras Med do Esporte 2016; 22: 455-460.

19. Giulliano D, Christofaro D, Casonatto J, Fernandes RA, Cucato GG, Goncalves CGS, et al. Efeito da Duração do Exercício Aeróbio sobre as Respostas Hipotensivas Agudas Pós-Exercício. Rev SOCERJ 2008; 21: 404-408.

20. Laterza MC, Rondon M, Negrão CE. Efeito anti-hipertensivo do exercício. Rev Bras Hipertens 2007; 14: 104-111.

21. Dujić Ž, Ivančev V, Valic Z, Bakovic D, Marinović-Terzić I, Eterović D, et al. Postexercise hypotension in moderately trained athletes after maximal exercise. Med Sci Sports Exerc 2006; 38: 318-322.

22. Rosa HI, Pantoja FL, Rabelo AS, Costa HA, Silva-Filho AC, de Barros CLM, et al. Acute hypotension effect of a single bout of anaerobic power exercise (30-Sec wingate test). J Exerc Physiol Online; 18.

23. Kenney MJ, Seals DR. Postexercise hypotension. Key features, mechanisms, and clinical significance. Hypertension 1993; 22: 653-664.

24. Perini R, Veicsteinas A. Heart rate variability and autonomic activity at rest and during exercise in various physiological conditions. Eur J Appl Physiol 2003; 90: 317-325.

25. Javorka M, Zila I, Balharek T, Javorka K, et al. Heart rate recovery after exercise: relations to heart rate variability and complexity. Brazilian J Med Biol Res 2002; 35: 991-1000.

26. Chen MJ, Fan X, Moe ST. Criterion-related validity of the Borg ratings of perceived exertion scale in healthy individuals: A meta-analysis. J Sports Sci 2002; 20: 873-899.

\section{Acknowledgments}

We would like to thanks the Conselho nacional de desenvolvimento científico tecnológico - CNPq for funding (Universal 442374/2014-3) and Fundação de Amparo à Pesquisa do Estado do Maranhão - FAPEMA (Universal 00358/15). Cristiano Mostarda receives funding from Fundação de Amparo à Pesquisa do Estado do Maranhão - FAPEMA (Bolsa Produtividade em Pesquisa). 


\section{Corresponding author}

Cristiano Teixeira Mostarda

Universidade Federal do Maranhão - Av. dos Portugueses, 1966 - Vila Bacanga, São Luís - MA, 65080-805, Tel. +55 (98) 99194-0403.

Email: cristiano.mostarda@gmail.com
Manuscript received on October 15, 2018

Manuscript accepted on Ferbuary 27, 2019

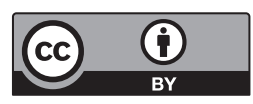

Motriz. The Journal of Physical Education. UNESP. Rio Claro, SP, Brazil - eISSN: 1980-6574 - under a license Creative Commons - Version 4.0 
Supplementary table

Sworkit ${ }^{\circledR}$ Personal Trainer "Light Warm-up Cardio" exercise list (exercises were chosen randomly at each session):

1. Step Touch: Lateral alternating step-touching

2. High knees: Alternated skips placing the knees as high as possible

3. Butt kickers: Alternating knee flexion aiming the touch of the heel at the levels of the gluteus.

4. Jump rope hops: Simulation of the rope jump

5. Single leg hops: Alternating single-leg jumps

6. Running in place: Statically running simulation

7. Jumping jacks: Alternating adduction and abduction of both upper and lower limbs

8. Front kicks: Alternated frontal hip flexions simulating a kick

9. Windmill: Standing trunk flexions aiming the touching of opposite the feet with the hands

10. Bend and reach: Squatting simulating reaching something at the floor and throwing in the air

11. Calf raises: Heels elevations in the standing position

12. Arm circles: Upper limb abduction followed by rotations in the horizontal plane

13. Side hops: Lateral jumps with both feet

14. Sidewalk plank: Initial plank position with lateral movements simulating a hand walk

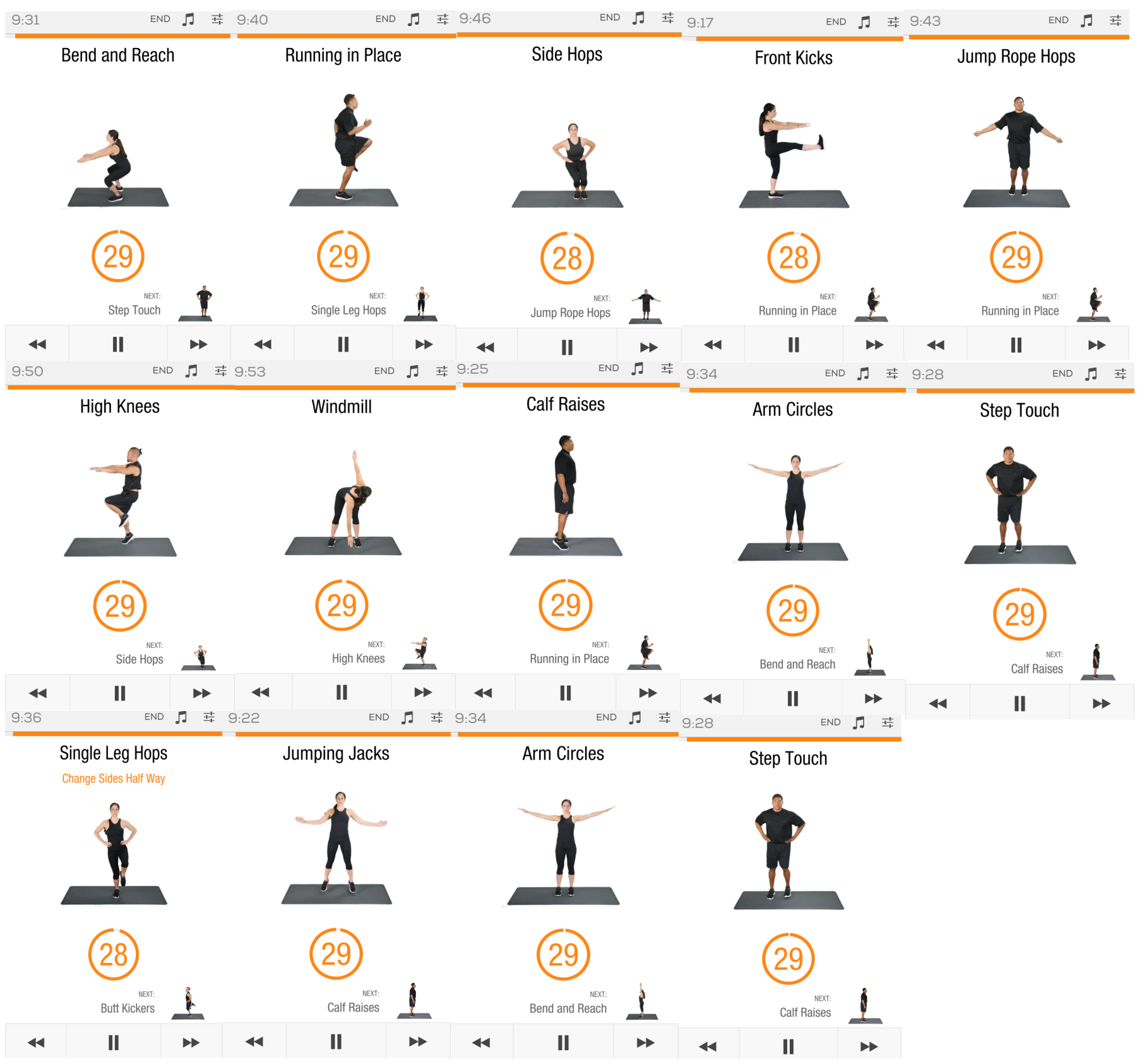

